\title{
Design of Dual-band SIW Cavity Backed Slot Antenna for X-band Applications
}

\author{
Lokeshwar Bollavathi \\ Department of ECE, R.V.R \& J.C College of Engineering, Guntur, India, \\ Email: lokesh5701@gmail.com
}

Received: 25 June 2021; Accepted: 27 July 2021; Published: 08 August 2021

\begin{abstract}
In this article, a novel design for the bandwidth improvement of a substrate integrated waveguide (SIW) cavity-backed slot antenna (CBSA) is presented. The introduced structure utilizes an inverted L-shaped slot and unbalanced metalized vias. The proposed antenna is of low height and holds a planar geometry while sustaining lower losses and lightweight. The inverted L-shaped slot at the bottom plate is responsible for radiation. The quality factor of the SIW cavity is significantly reduced by the inverted L-shaped slot which leads to attaining a wideband response. The proposed antenna resonates at two frequencies $9.4025 \mathrm{GHz}$ and $10.0075 \mathrm{GHz}$ in the first band from the range $9.27 \mathrm{GHz}$ to $10.13 \mathrm{GHz}$ with the fractional bandwidth of $8.915 \%$ and at $12.07 \mathrm{GHz}$ in the second band from the range $11.96 \mathrm{GHz}$ to $12.2 \mathrm{GHz}$ with fractional bandwidth of $1.9 \%$.
\end{abstract}

Index Terms: Cavity backed slot antenna, Substrate Integrated Waveguide (SIW), Metalized vias, Quality factor, Wideband.

\section{Introduction}

At microwave \& UHF frequencies at which wavelengths are small, the slot antenna plays a major role because of its size, low cost, convenient adaption when using waveguide or PC board technology. However, the radiation efficiency of the slot antenna is less because of its bi-directional radiation. By using different shapes of slots, the efficiency of the antenna can be improved. To prevent back-radiation, the slot antenna is backed with SIW cavity [1]. In [2], for wideband applications, a non-resonant cavity is used along with dumbbell slot antenna. A broadband slot is used instead of a planar rectangular structure to increase the bandwidth of the slot antenna in [3].To improve impedance matching at the input port and bandwidth an offset feeding technique has been introduced in [4]. For polarization diversity and wideband applications, SIW cavity-backed slot antennas are designed in [5,6].

To achieve a low cross-polarisation level, a cross slot structure is used as the radiating element in [7]. To create dual resonance, a via hole is placed along with the slot [8]. Without changing the first resonance, wideband operation can be achieved by selecting the proper location of the via-hole. Also, high gain and wider bandwidth can be achieved. In [9], unbalanced metallic vias are placed at the slot to achieve quad-mode excitation of the cavity. Bandwidth enhancement can also be achieved by simultaneously exciting 2 hybrid modes and merging them within the frequency range [10,11]. In [12], the rectangular slots are inclined at an angle of $24^{\circ}$ and 2 metallic vias are introduced to produce alternative inductive and capacitive loads. Since capacitance is inversely proportional to the bandwidth of the antenna, a substrate under slot is removed to decrease the capacitance of slot in [13]. Dual-band [14], size-reduction [15], wideband [16] cavity-backed slot antennas using SIW technology are reported in the literature. However, very few articles have been reported on dual-band response. In this paper, a low-profile SIW cavity-backed slot antenna for dualband response is studied using unbalanced vias.

\section{Antenna Configuration and Performance}

Configuration of the proposed SIW cavity-backed inverted L-shaped slot antenna is shown in Fig.1. The proposed antenna has been designed with Rogers/RT Duroid 5880 substrate having relative permittivity 2.2 and thickness of 1.6 $\mathrm{mm}$ and loss tangent 0.001 . The leakage losses between vias can be reduced by following conditions $\mathrm{p} \leq 2 \mathrm{~d}$ and $\mathrm{d} \leq$ $0.1 \lambda_{0}$. In an inverted L-shaped slot, the vertical slot length is approximately a half wavelength at the operating frequency. The sidewalls of the cavity are realized using metallized via holes. The via-holes are placed unsymmetrically on both sides of the slot. The frequency of resonance is mainly determined by the size of the cavity [14]. The dimensions of the cavity have been calculated from equations (1). The antenna is fed with 50 microstrip line and the geometrical parameters of the antenna are listed in Table 1. The simulation of the proposed antenna is conducted with the help of 
Ansoft HFSS. The length of the vertical slot is half the wavelength at the operating frequency. The antenna is simulated for X-band $(8 \mathrm{GHz}-12 \mathrm{GHz})$. The operating frequency is considered here as $10 \mathrm{GHz}$ to excite at $\mathrm{TE}_{210}$ mode. The working is observed by changing different parameters like length of the vertical slot, the position of horizontal slot and unsymmetrical vias.

$$
f_{m n p^{\prime}}=\frac{1}{2 \sqrt{\mu_{0} \varepsilon_{0} \varepsilon_{r}}} \sqrt{\left(\frac{m}{L_{e f f}}\right)^{2}+\left(\frac{n}{W_{e f f}}\right)^{2}+\left(\frac{p \prime}{h}\right)^{2}}
$$

where $\mathrm{m}, \mathrm{n}$ and $\mathrm{p}$ are half field variations in $\mathrm{x}, \mathrm{y}$ and $\mathrm{z}$ directions, $\varepsilon_{r}-$ dielectric constant, $\mathrm{d}$ is the diameter of each via and $\mathrm{p}$ is the distance between centres of two vias.

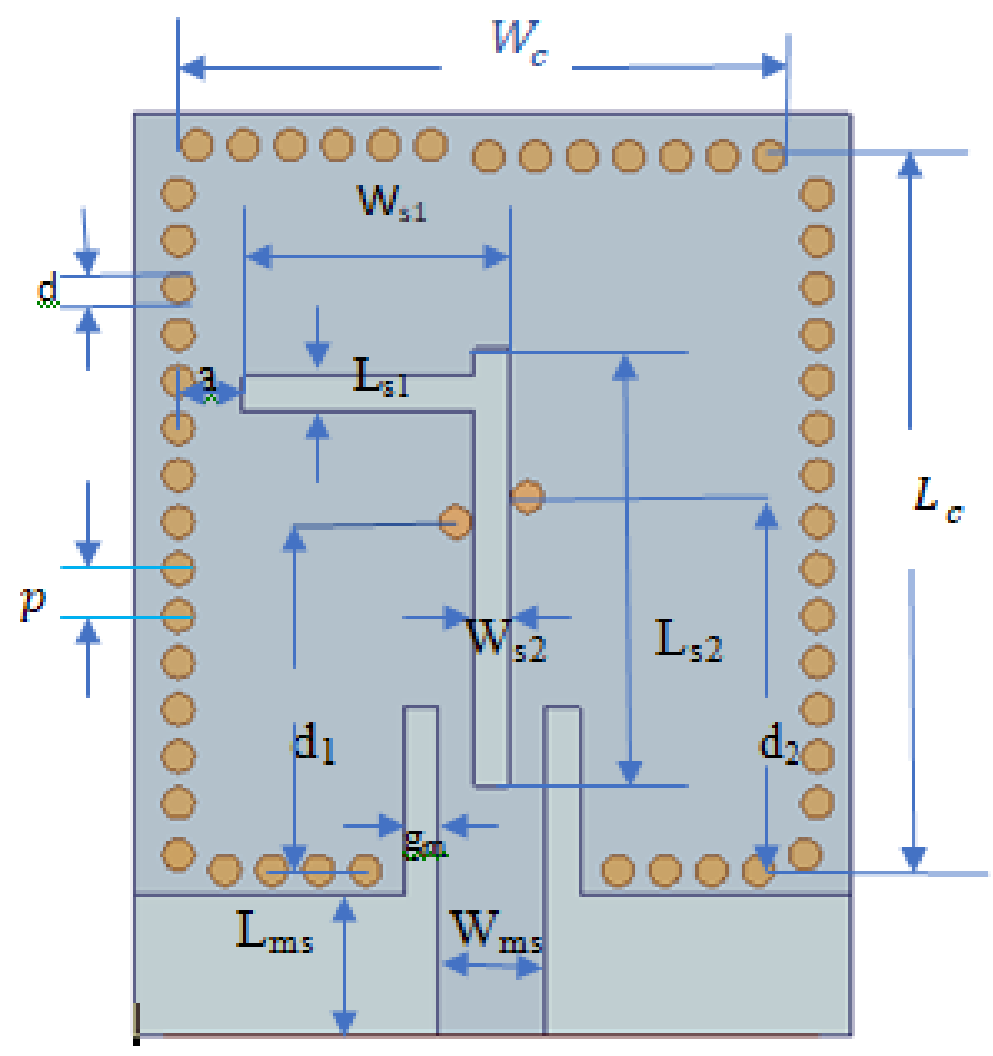

Fig. 1. Proposed antenna design.

Table 1. Dimensions of the antenna at $10 \mathrm{GHz}$

\begin{tabular}{|c|c|c|c|}
\hline Dimensions & Value $(\mathrm{mm})$ & Dimensions & Value $(\mathrm{mm})$ \\
\hline Lc & 23.2 & Ws2 & 1.1 \\
\hline Wc & 20.5 & $\mathrm{~g}_{\mathrm{m}}$ & 11.45 \\
\hline $\mathrm{d}$ & 1 & $\mathrm{~d} 1$ & 12.25 \\
\hline $\mathrm{P}$ & 1.5 & $\mathrm{~d} 2$ & 4.5 \\
\hline Ls1 & 1.1 & $\mathrm{Lms}$ & 3.45 \\
\hline Ws1 & 8 & $\mathrm{Wms}$ & 1.6 \\
\hline
\end{tabular}

\subsection{Effect of length of Vertical Slot}

By changing the length of the vertical slot, its effect on the return loss of proposed antenna observed and is shown in Fig.2.The vertical slot length is responsible for the resonance at second band. Since length and frequency are inversely proportional, as the length is increased resonating frequency will be decreased. So, the length of vertical slot is kept approximately half of the wavelength at operating frequency. 


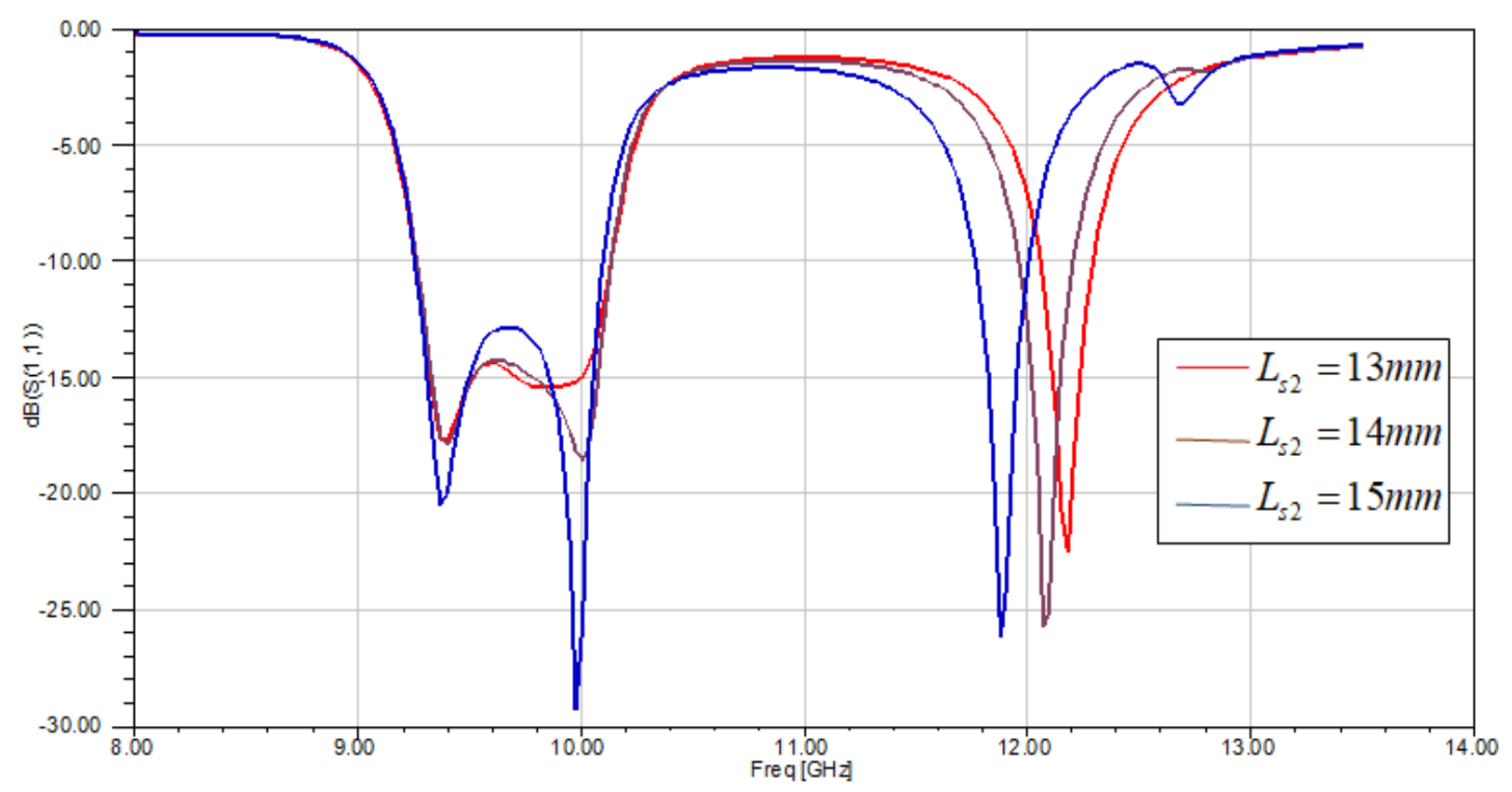

Fig. 2. Return loss of the proposed antenna by varying length of the vertical slot.

\subsection{Effect of position of horizontal slot}

The horizontal slot position is changed by changing 'a' shown in Fig.1. By observing the Fig.3 we can say that when the horizontal slot is changing towards right side, at the first band there is no impedance matching which means maximum power will not be delivered.

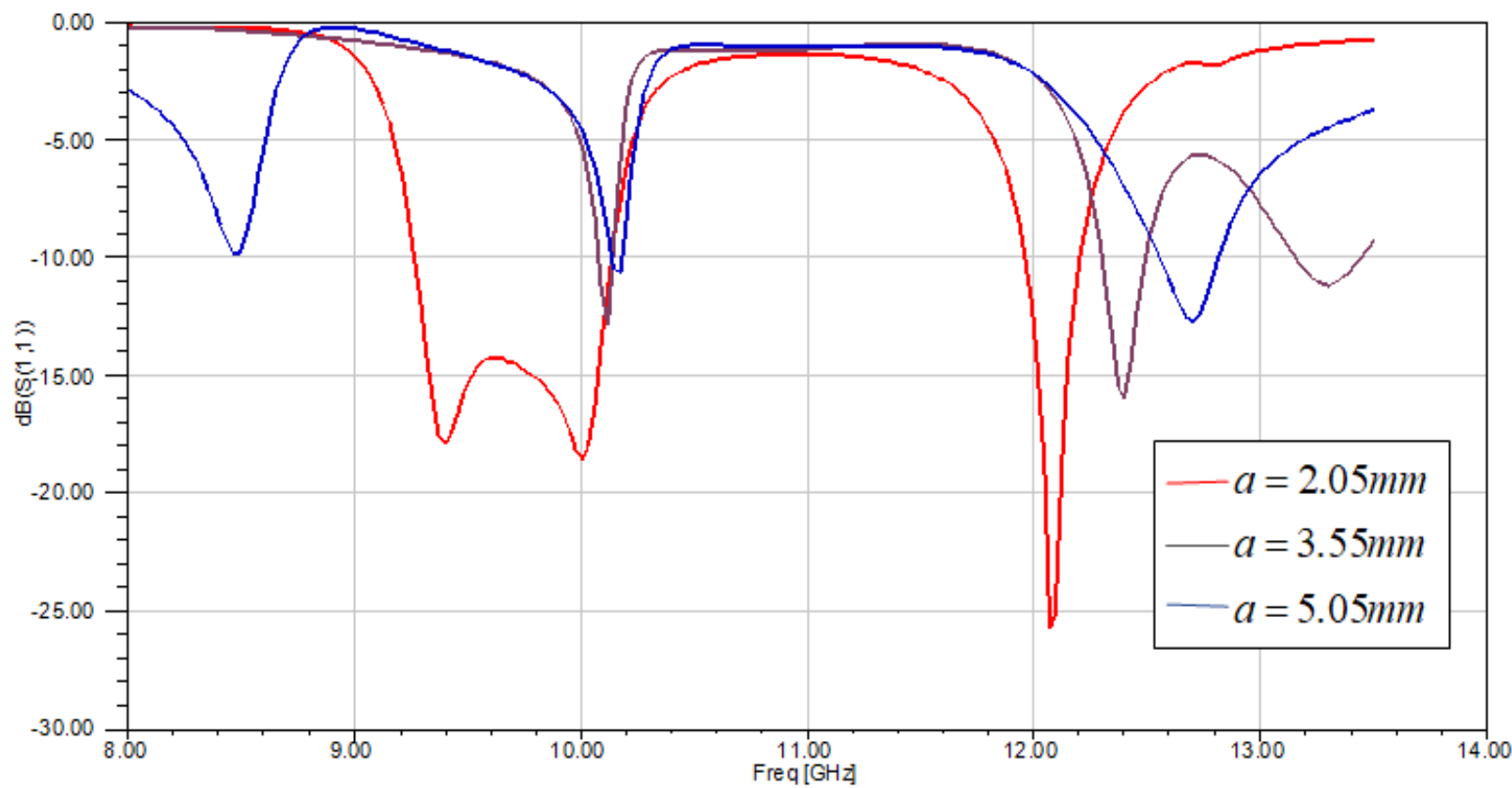

Fig. 3. Return loss of the proposed antenna by varying horizontal slot position.

\subsection{Effect of position of unsymmetrical vias}

By changing $d_{1}$ and $d_{2}$ shown in Fig.1, the effect of vias on return loss of the proposed antenna is observed and shown in Fig.4 and Fig.5.From Fig.5.The left via is plaed such that there will be good impedance matching. By placing right via hole at the proper location resonance at first band can be achieved with good impedance matching. However the right via is not effecting the second band. 


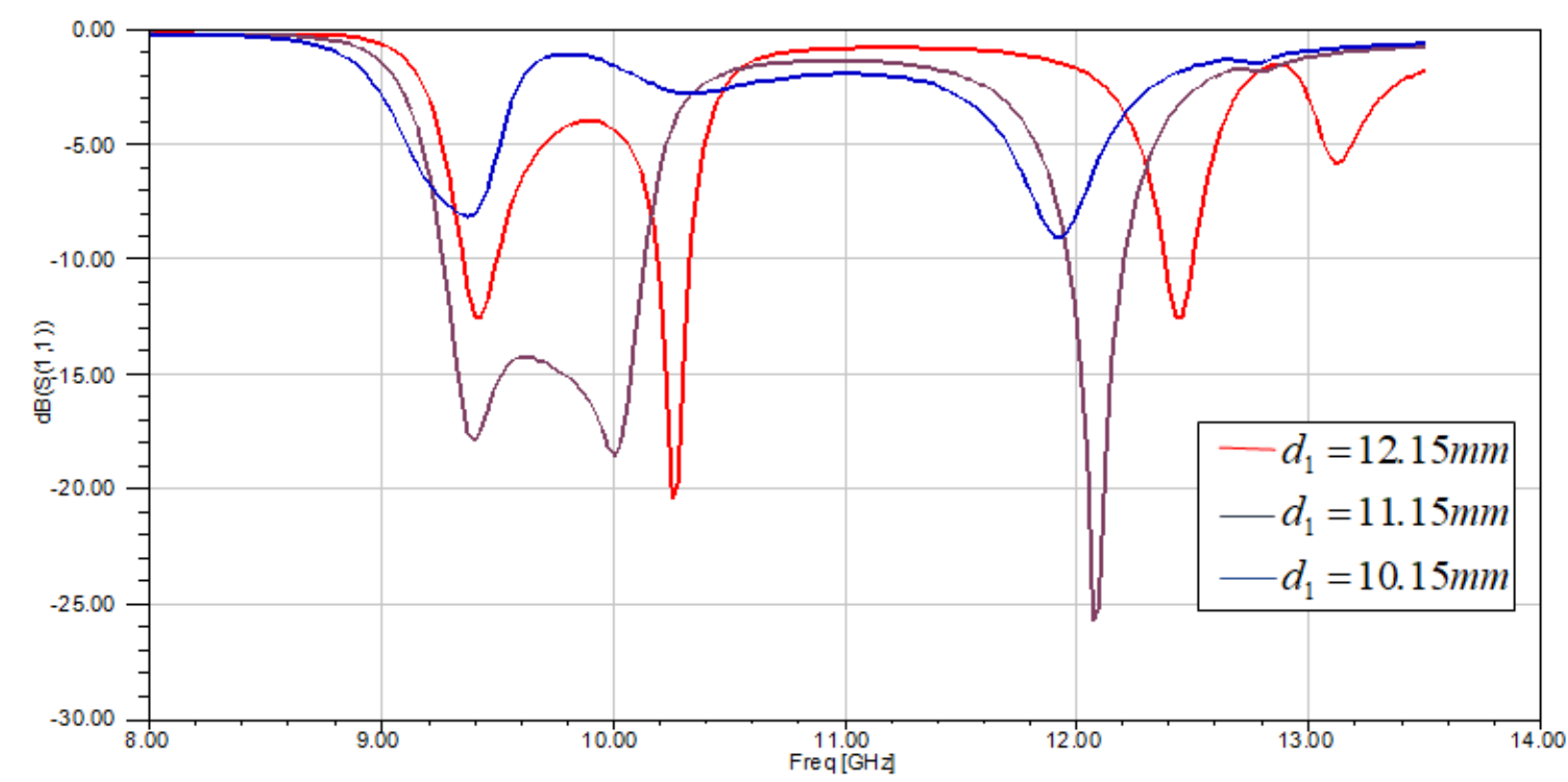

Fig. 4. Return loss of the proposed antenna by varying left via position.

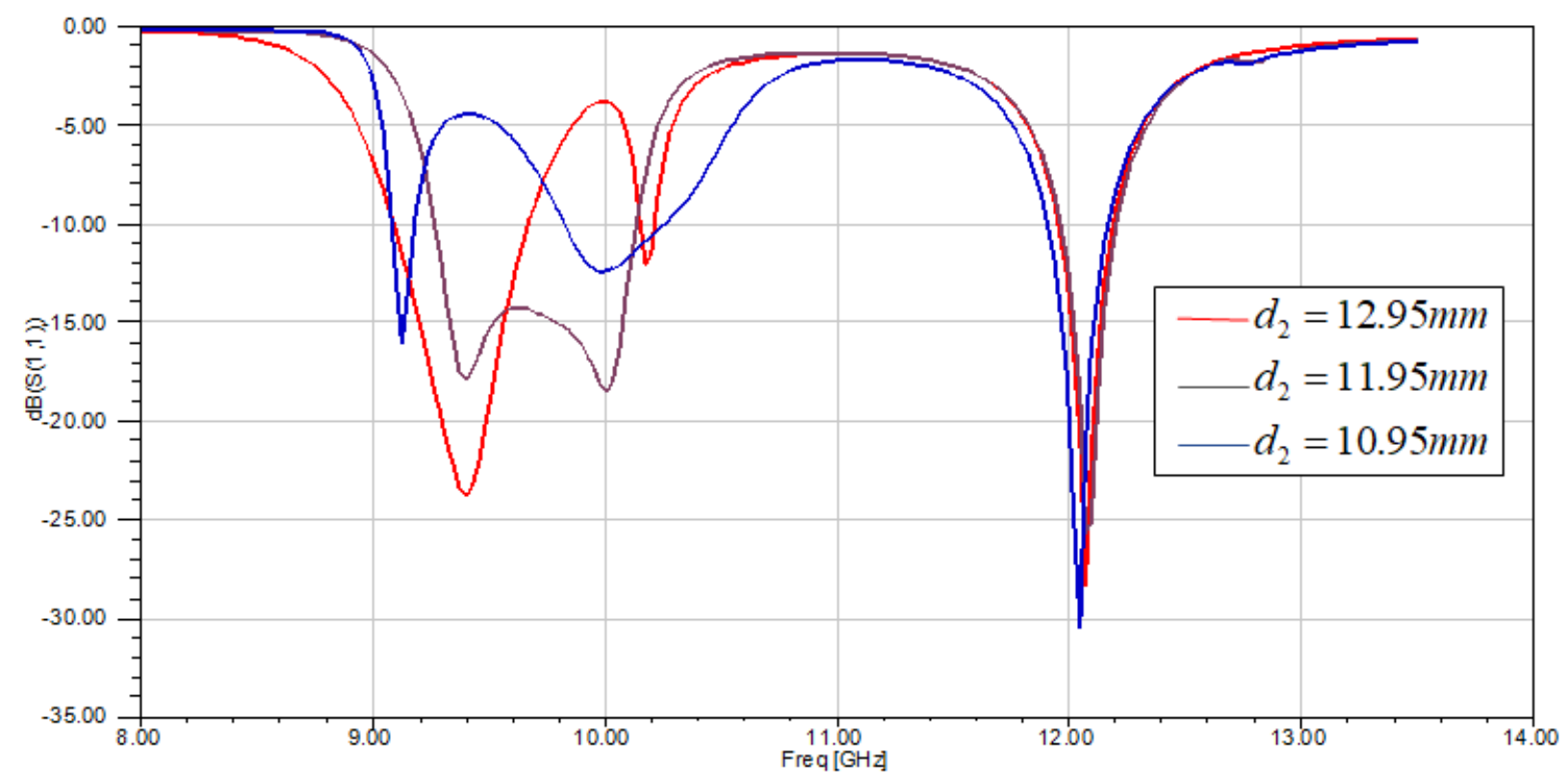

Fig. 5. Return loss of the proposed antenna by varying right via position.

\section{Simulation Results}

The return loss characteristics, gain and VSWR of the proposed antenna are computed. From the return loss characteristics shown in Fig.6, the proposed antenna resonates at two frequencies $9.4025 \mathrm{GHz}$ and $10.0075 \mathrm{GHz}$ in the first band with fractional bandwidth of $9.3 \%$. In the second band, the antenna is resonating at $12.07 \mathrm{GHz}$ with fractional bandwidth of $1.9 \%$. The return loss of $-17.9 \mathrm{~dB}$ at $9.4025 \mathrm{GHz},-18.5 \mathrm{~dB}$ at $10.0075 \mathrm{GHz}$, and $-25.7 \mathrm{~dB}$ at $12.07 \mathrm{GHz}$. From Fig.7 VSWR is observed $<1$ at all the three resonating frequencies. The gain at all the resonating frequencies is shown in Fig. [8], [9] and [10]. The 3D-gain plot is symmetrical and maximum gain of $6.1 \mathrm{dBi}$ at $9.4025 \mathrm{GHz}, 6.6 \mathrm{dBi}$ at $10.0075 \mathrm{GHz}$, and $7.1 \mathrm{dBi}$ at $12.07 \mathrm{GHz}$ is achieved in the boresight direction. 


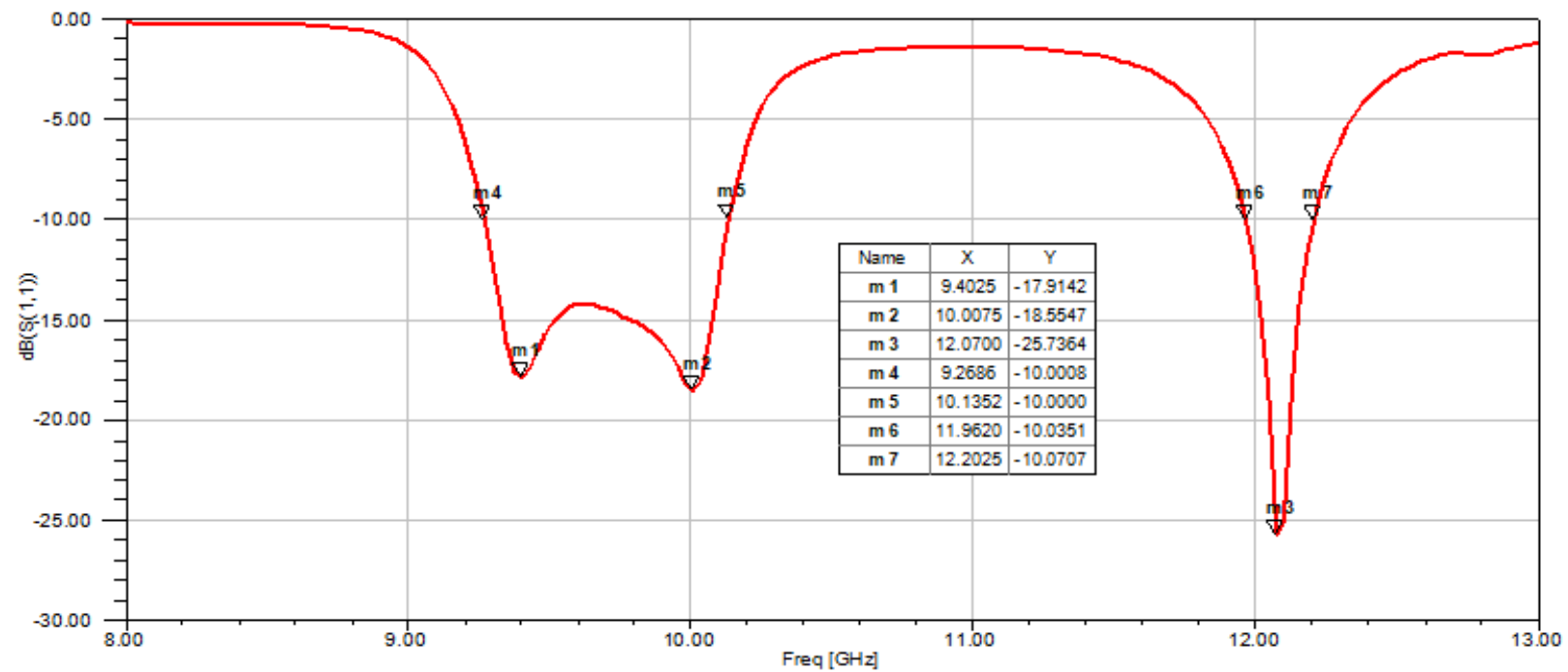

Fig. 6. Return loss characteristics of proposed antenna

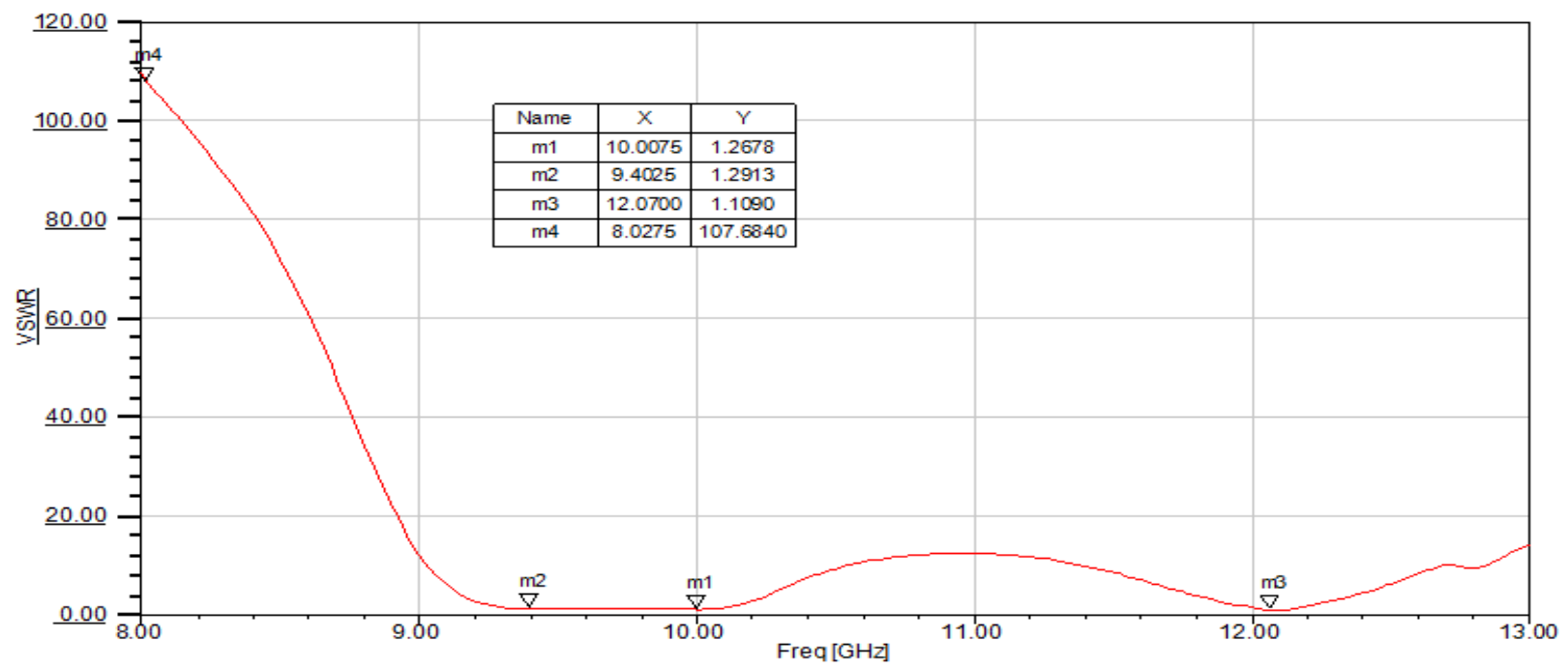

Fig. 7. VSWR of proposed antenna



Fig. 8. Gain at frequency $9.4025 \mathrm{GHz}$ 

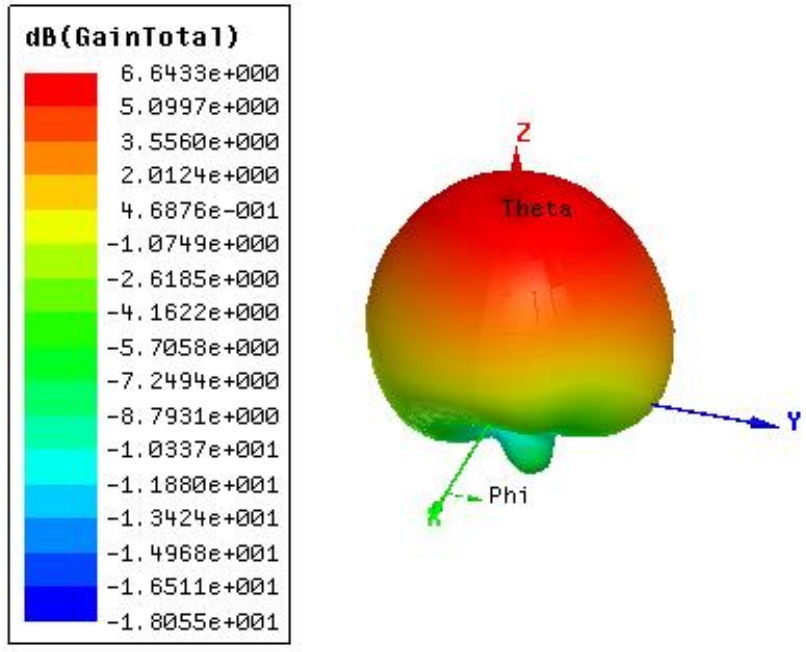

Fig. 9. Gain at frequency $10.0075 \mathrm{GHz}$
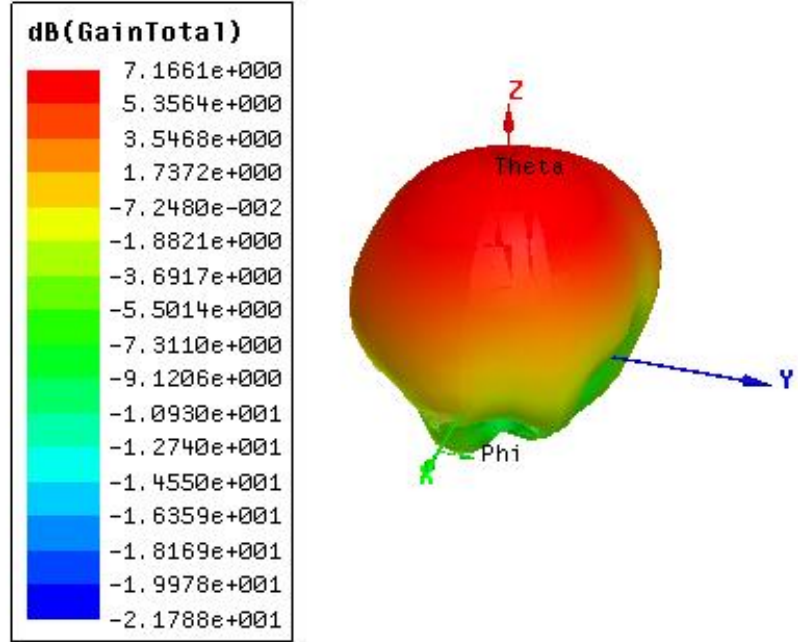

Fig. 10. Gain at frequency $12.07 \mathrm{GHz}$

\section{Conclusions}

An extensive study of dual band response is discussed. In the proposed antenna the length of the vertical slot is responsible for first band and the position of horizontal slot is responsible for the second band. The vias on both sides of the slot improve the fractional bandwidth. The proposed antenna retains advantages such as low profile, light weight. The proposed antenna resonates at two frequencies $9.4025 \mathrm{GHz}$ and $10.0075 \mathrm{GHz}$ in the first band with fractional bandwidth of $8.915 \%$, and at $12.07 \mathrm{GHz}$ in the second band.

\section{References}

[1] Kumar A, Saini G, Singh S (2016). A review on future planar transmission lines. Cognet Engineering 3:1138920.

[2] Bollavathi, L., V. Dorai, and S. Alapati (2020). Wideband planar substrate integrated waveguide cavity-backed amended dumbbell-shaped slot antenna. AEU-International Journal of Electronics and Communications, Vol. 127, 153489.

[3] S Rekha and M Nesasudha (2017). Bandwidth improvement of a rear end slot antenna on a Substrate Integrated Waveguide cavity. IOP Conf. Ser.: Mater. Sci. Eng. 247012003.

[4] Mukherjee S, Biswas A, Srivastava KV (2013). Bandwidth enhancement of substrate integrated waveguide cavity backed slot antenna by offset feeding technique. IEEE Appl Electromagn Conf 1-2.

[5] S Mukherjee, A Biswas (2015). Substrate Integrated Waveguide (SIW) Cavity Backed Slot Antenna for Polarization Diversity Application.

[6] S Mukherjee, A Biswas (2016). Design of SIW Cavity Backed Slot Antenna for Wideband Application. Proceedings of the Asia- Pacific Microwave Conference. 
[7] Guo Qing Luo, Zhi Fang Hu, Yaping Liang, Li Yang Yu, and Ling Ling Sun (2009). Development of Low Profile Cavity Backed Crossed Slot Anten- nas for Planar Integration. IEEE Trans Antennas Propag, 57(10).

[8] Yun S, Kim DY, Nam S (2012) Bandwidth enhancement of cavity-backed slot antenna using a via-hole above the slot. IEEE Antenna Wireless Propag Lett 11:1092-1095.

[9] Qi Wu, Haiming Wang, Wei Hong,"Broadband Millimeter-Wave SIW Cavity-Backed Slot Antenna for 5G Applications Using Machine- Learning-Assisted Optimization Method",2019.

[10] Luo GQ, Hu ZF, Li WJ, Zhang XH, Sun LL, Zheng JF (2012) Bandwidth-enhanced low-profile cavity-backed slot antenna by using SIW cavity modes. IEEE Trans Antennas Propag 60(4):1698-1704.

[11] Lokeshwar B, Venkatasekhar D, Sudhakar A (2020). Wideband low-profile SIW cavity-backed antenna bilateral slots antenna for X-band application. Prog In Electromagn Res. M 97: 157-166.

[12] Chaturvedi D (2020). SIW cavity-backed $24^{\circ}$ inclined-slots antenna for ISM band application. Int J RF Microw Comput Aided Eng 30(5):e22160.

[13] Yun S, Kim DY, Nam S (2012). Bandwidth and efficiency enhancement of cavity-backed slot antenna using a substrate removal. IEEE Antenna Wireless Propag Lett 11:1458-1461.

[14] Lokeshwar B, Venkatasekhar D, Sudhakar A (2020). Dual-band low profile SIW cavity-backed antenna by using bilateral slots. Prog In Electromagn Res. C 100:263-273.

[15] Dokuparthi, J, Sudhakar A (2019). Dual band half mode SIW semicircular cavity back slot antenna. Progress In Electromagnetic Research Lett, Vol. 87, 7-14.

[16] Lokeshwar B, Venkatasekhar D, Sudhakar A (2020). Bandwidth-Enhanced of SIW Cavity-Backed Slot Antenna By Perturbing $\mathrm{TE}_{210}$ Cavity Mode. Biosc.Biotech.Res.Comm. SI Vol 13, No 14, pp-320-324.

\section{Author's Profile}

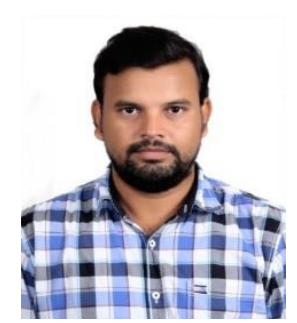

Bollavathi Lokeshwar is currently working as Assistant Professor in the Department of ECE, RVR \& JC College of Engineering, Guntur, Andhra Pradesh, India. He is currently pursuing Ph.D. in the Department of ECE, Annamalai University, Chidambaram, Tamilnadu, India. He has an experience of 10 years in teaching. He has qualified UGC NET, Govt. of India in 2012. He has published 7 research publications in various reputed peer reviewed International journals like Elsevier, PIER. He has presented his works in 2 international and 2 national conferences with 1 best technical paper award. He has filed 6 Indian patents. He is a reviewer of 4 International journals. His research interest includes Substrate Integrated Waveguide (SIW) antennas, Multi-frequency, Broadband antennas, and Self-diplexing antennas.

How to cite this paper: Lokeshwar Bollavathi, " Design of Dual-band SIW Cavity Backed Slot Antenna for X-band Applications", International Journal of Wireless and Microwave Technologies(IJWMT), Vol.11, No.4, pp. 34-40, 2021.DOI: 10.5815/ijwmt.2021.04.04 